\title{
Clinical and ultrasound parameters in prediction of excessive hemorrhage during management of cesarean scar pregnancy
}

This article was published in the following Dove Press journal:

Therapeutics and Clinical Risk Management

30 June 2017

Number of times this article has been viewed

Ting Gui
Ping Peng
Xinyan Liu
Li Jin
Weilin Chen

Department of Obstetrics and Gynecology, Peking Union Medical College Hospital, Peking Union Medical College, Chinese Academy of Medical Sciences, Beijing, People's Republic of China
Correspondence: Ping Peng

Department of Obstetrics and Gynecology, Peking Union Medical College Hospital, Peking Union Medical College, Chinese Academy of Medical Sciences, No I, Shuaifuyuan Road, Dongcheng District, Beijing 100730, People's Republic of China $\mathrm{Tel} / \mathrm{fax}+86 \quad 106915 \quad 1303$ Email pp_pengping@।63.com
Precis: During the management of cesarean scar pregnancy, gestational mass size $>6 \mathrm{~cm}$, uterine scar thickness $<0.2 \mathrm{~cm}$, peak systolic velocity $>70 \mathrm{~cm} / \mathrm{s}$, and resistance index $<0.35$ are independent risk factors for excessive hemorrhage.

Objective: The objective of this study was to investigate risk factors associated with excessive hemorrhage during the management of cesarean scar pregnancy (CSP).

Patients and methods: A retrospective case-control study was conducted, including 40 patients who experienced excessive bleeding and 80 controls without severe hemorrhage.

Results: Six parameters (two clinical and four ultrasound parameters) potentially related to excessive hemorrhage were analyzed. Single-variable statistical analyses showed that the case group had higher gestational age (74.1 \pm 23.6 days), higher pretreatment serum $\beta$-human chorionic gonadotropin (HCG) level $(46,201 \pm 32,294 \mathrm{mIU} / \mathrm{mL})$, larger gestational mass size $(6.5 \pm 2.2 \mathrm{~cm})$, thinner uterine scar thickness $(0.17 \pm 0.12 \mathrm{~cm})$, and richer peritrophoblastic perfusion (peak systolic velocity [PSV] $72.8 \pm 33.7 \mathrm{~cm} / \mathrm{s}$, resistance index [RI] 0.35 \pm 0.12 ), showing statistical significance compared with the control group. Further multivariable logistic regression analysis of the association between each of the risk factors and hemorrhage confirmed that increased gestational mass size and PSV were risk factors for hemorrhage (odds ratio [OR] 3.624, 95\% confidence interval [CI] [1.179-11.138] and OR 1.062, 95\% CI [1.007-1.121]) and increased uterine scar thickness and RI were protective factors against hemorrhage (OR 0.181, 95\% CI [0.034-0.957] and OR 0.851, 95\% CI [0.729-0.994]); however, there was no statistical significance between the two clinical parameters.

Conclusion: Gestational mass size $>6 \mathrm{~cm}$, uterine scar thickness $<0.2 \mathrm{~cm}$, PSV $>70 \mathrm{~cm} / \mathrm{s}$, and RI $<0.35$ are independent risk factors for excessive hemorrhage during the management of CSP.

Keywords: cesarean scar pregnancy, excessive hemorrhage, ultrasound parameters, risk factors

\section{Introduction}

A particular complication of a pregnancy after cesarean delivery is the implantation of gestational sac in the scar, known as cesarean scar pregnancy (CSP). ${ }^{1,2}$ The incidence of CSP has been estimated to range from $1 / 1,800$ to $1 / 2,500$ of all cesarean deliveries. ${ }^{3}$ To date, there is still no standard treatment. Proposed treatment includes medical interventions (injection of methotrexate [MTX]) and surgical interventions (uterine artery embolization [UAE], suction curettage, local CSP resection, and hysterectomy). ${ }^{4-6}$ Termination of pregnancy is recommended soon after confirmation of diagnosis, so as to avoid severe complications, such as uterine rupture and massive bleeding. 
The results of management are encouraging, but not every patient's uterus and future fertility could be preserved. Uncontrollable hemorrhage still occurs during the treatment. Therefore, it is of great necessity to identify the potential risk factors for massive hemorrhage. Several studies have reported that gestational age, serum $\beta$-human chorionic gonadotropin (HCG), size of gestational mass, thickness of myometrial layer, and peritrophoblastic perfusion are related to excessive hemorrhage. ${ }^{7,8}$ Ultrasound examination plays an important role in CSP. However, the previous grading system of blood flow was semi-quantitative (absent or mild, moderate, and significant), subjective to physicians according to ultrasonographic findings.

Our research is a case-control study, trying to evaluate both clinical and ultrasound parameters in predicting severe hemorrhage in CSP, especially the quantitative parameters for peritrophoblastic perfusion, in the hope of helping identifying patients at a high risk of bleeding and assisting decision making in the treatment of CSP.

\section{Patients and methods}

A case-control study was designed and conducted in Peking Union Medical College Hospital (PUMCH). Our research was approved by the ethics committee of PUMCH, who deemed written informed consent not necessary due to the retrospective nature of the study and all data being de-identified.

\section{Patient selection}

The study was based on information of patients admitted and diagnosed with CSP and treated by suction curettage between January 2007 and December 2014. During the 8 years, there were a total of 325 women diagnosed with CSP who were admitted to PUMCH. Excessive hemorrhage was defined as a blood loss $>400 \mathrm{~mL}$ during the suction curettage according to the previous literature ${ }^{9}$ and the necessity for patients to receive at least one of the following additional interventions, including UAE plus secondary suction curettage, local CSP resection, and hysterectomy. In all, 40 patients with CSP having excessive hemorrhage during suction curettage were assigned to the case group $(n=40)$. The control subjects were chosen with the use of computerized randomization through a 2:1 (control:case) random sample of all the other patients with CSP who received the same treatment during the same period, but who did not have a blood loss $>400 \mathrm{~mL}$ during suction curettage that required additional interventions $(n=80)$.

The patient information, including patient age at diagnosis, gravidity, parity, interval between current CSP and last cesarean, gestational age at diagnosis, pretreatment serum $\beta$-HCG level, gestational mass size, uterine scar thickness, peak systolic velocity (PSV), and resistance index (RI), was collected from the medical records and the clinical database.

\section{Diagnosis of CSP}

All patients included in our study were confirmed the diagnosis of CSP, based on the criteria postulated by Godin et al, ${ }^{10}$ including: 1) a history of cesarean delivery; 2) positive serum $\beta$-HCG level; 3) visualization of an empty uterine cavity and cervical canal; 4) detection of the placenta or a well-formed gestational mass embedded in the scar; 5) lack of continuity of myometrial image between the bladder and the gestational mass; and 6) color Doppler ultrasound demonstrating blood flow surrounding the gestational mass. An ultrasound image of CSP is shown in Figure 1.

\section{Ultrasound examination}

Ultrasound examinations were performed by color Doppler ultrasound diagnosis apparatus using a 5-9 $\mathrm{MHz}$ transvaginal probe (Phillips iU22, GE Logiq 9). Concerning the peritrophoblastic perfusion, both qualitative analysis of spectrograms identifying characteristic blood flow patterns and quantitative variables, including arterial PSV and RI, were detected and calculated (Figure 2). All the data concerning ultrasound parameters included in our research were collected at diagnosis before the treatment of CSP.

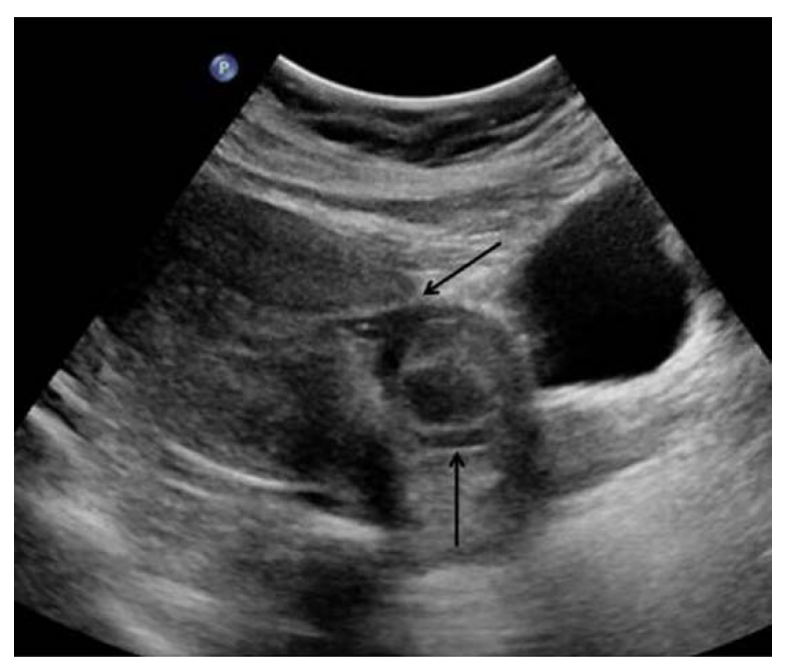

Figure I CSP demonstrated by ultrasound.

Notes: The upper arrow refers to the cesarean scar. The lower arrow refers to the gestational sac. The ultrasound image shows that the gestational sac was implanted in the previous cesarean scar.

Abbreviation: CSP, cesarean scar pregnancy. 


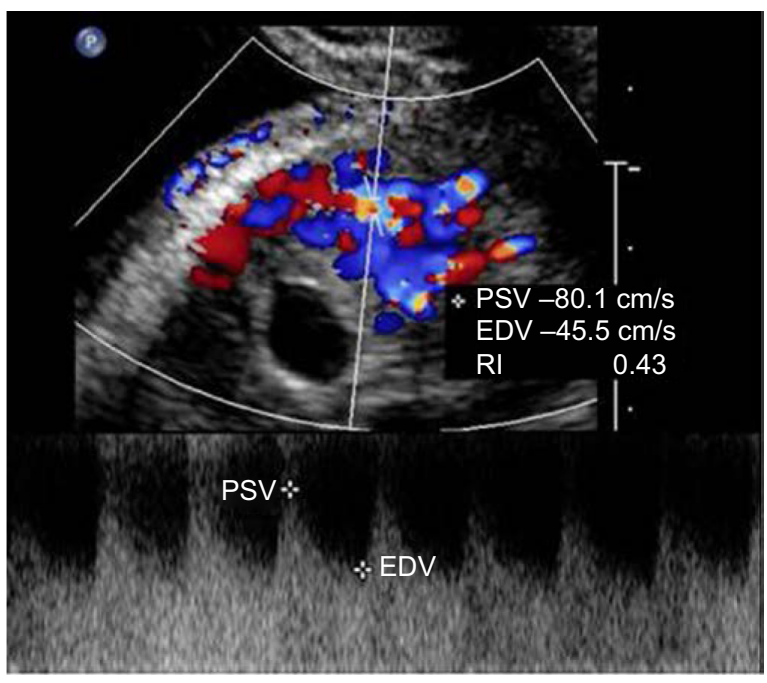

Figure 2 Doppler waveforms of peritrophoblastic blood flow.

Notes: Waveforms over three cardiac cycles were analyzed at each sample point, and the mean was taken to obtain the average blood flow velocity, PSV, and EDV for each spectrogram. Based on these raw data, the RI was calculated for each spectrogram. The formula was as follows: RI $=(P S V-E D V) / P S V$. The average of each of these values for the three spectrograms was obtained as the final PSV and RI for the study.

Abbreviations: PSV, peak systolic velocity; EDV, end diastolic velocity; RI, resistance index.

\section{Statistical analyses}

Statistical analyses were performed with SPSS software version 19, with statistical significance being accepted at $P<0.05$. Data on demographic characteristics were expressed as mean \pm standard deviation. Quantitative variables were analyzed by using Student's $t$-test or analysis of variance test (ANOVA) test. Qualitative variables were evaluated by using two-tailed $\chi^{2}$ test. Odds ratios (ORs) with $95 \%$ confidence intervals (CIs) were calculated by using logistic regression analysis.

\section{Results \\ Demographic information}

Statistical analyses showed no significant differences between the case group and the control group in the demographic information of patients, including the patients' age at diagnosis ( $33.3 \pm 5.7$ years vs $33.7 \pm 5.1$ years $)$, the gravidity
(4.3 \pm 1.5 vs $4.1 \pm 1.2)$, the parity ( $1.4 \pm 0.5$ vs $1.2 \pm 0.7)$, and the interval between the current CSP and last cesarean (63.4 \pm 52.4 months vs 55.6 \pm 44.3 months; Table 1 ).

\section{Management of CSP}

In the control group, 80 patients only underwent suction curettage under the surveillance of ultrasound without additional interventions.

In the case group, 40 patients first received suction curettage under the surveillance of ultrasound and then needed additional interventions due to excessive hemorrhage. These patients were classified into three subgroups in accordance with their additional therapy, including the UAE plus secondary suction curettage subgroup $(n=15,37.5 \%)$, the local CSP resection subgroup $(n=18,45 \%)$, and the hysterectomy subgroup $(n=7,17.5 \%)$.

\section{Blood loss during treatment of CSP}

Overall, the mean bleeding volume was $1,440 \pm 955 \mathrm{~mL}$ vs $215 \pm 84 \mathrm{~mL}$ for the case group vs the control group, showing significant statistical difference with $P=0.001$. Specifically, in the case group, the mean bleeding volume was $621 \pm 165 \mathrm{~mL}$, $966 \pm 328 \mathrm{~mL}$, and $2,314 \pm 784 \mathrm{~mL}$ for the UAE plus secondary suction curettage subgroup, the local CSP resection subgroup, and the suction curettage subgroup, respectively, in an ascending order. Compared with the UAE plus secondary suction curettage subgroup, the latter two subgroups showed significantly much more blood loss, with $P$-values 0.048 and 0.001 (Table 2).

\section{Analyses of high-risk factors for excessive hemorrhage during treatment of CSP}

For the case group and the control group, the mean gestational age at diagnosis was $74.1 \pm 23.6$ days and $57.3 \pm 22.3$ days, the mean pretreatment serum $\beta$-HCG level was $46,201 \pm 32,294 \mathrm{IU} / \mathrm{mL}$ and $24,189 \pm 10,584 \mathrm{IU} / \mathrm{mL}$, the mean gestational mass size was $6.5 \pm 2.2 \mathrm{~cm}$ and $3.1 \pm 1.1 \mathrm{~cm}$, the mean uterine scar thickness was $0.17 \pm 0.12 \mathrm{~cm}$ and $0.31 \pm 0.15 \mathrm{~cm}$, the mean PSV was $72.8 \pm 33.7 \mathrm{~cm} / \mathrm{s}$

Table I Demographic comparison of patients with CSP

\begin{tabular}{|c|c|c|}
\hline Parameters & $\begin{array}{l}\text { CSP with excessive hemorrhage } \\
\text { (mean } \pm \text { SD) }\end{array}$ & $\begin{array}{l}\text { CSP without excessive hemorrhage } \\
\text { (mean } \pm \text { SD) }\end{array}$ \\
\hline Age (years) & $33.3 \pm 5.7$ & $33.7 \pm 5.1$ \\
\hline Gravidity & $4.3 \pm 1.5$ & $4.1 \pm 1.2$ \\
\hline Parity & $1.4 \pm 0.5$ & $1.2 \pm 0.7$ \\
\hline Interval between current CSP & $63.4 \pm 52.4$ & $55.6 \pm 44.3$ \\
\hline
\end{tabular}

Abbreviations: CSP, cesarean scar pregnancy; SD, standard deviation. 
Table 2 Comparison of blood loss during management of CSP

\begin{tabular}{|c|c|c|c|}
\hline Blood loss & $\begin{array}{l}\text { Case group }(n=40) \text { : CSP } \\
\text { with excessive hemorrhage } \\
\text { (mean } \pm \text { SD) }\end{array}$ & $\begin{array}{l}\text { Control group }(n=80): \text { CSP } \\
\text { without excessive hemorrhage } \\
\text { (mean } \pm \text { SD) }\end{array}$ & $P$-value \\
\hline Total & $\mathrm{I}, 440 \pm 955 \mathrm{~mL}$ & $215 \pm 84 \mathrm{~mL}$ & $0.001 *$ \\
\hline $\begin{array}{l}\text { UAE + suction curettage subgroup } \\
(n=I 5)\end{array}$ & $62 \mathrm{I} \pm 165 \mathrm{~mL}$ & & - \\
\hline $\begin{array}{l}\text { Local CSP resection } \\
\text { subgroup }(n=18)\end{array}$ & $966 \pm 328 \mathrm{~mL}$ & & $0.048^{\#}$ \\
\hline $\begin{array}{l}\text { Hysterectomy } \\
\text { subgroup }(n=7)\end{array}$ & $2,3 \mid 4 \pm 784 \mathrm{~mL}$ & & $0.00 I^{\#}$ \\
\hline
\end{tabular}

and $47.5 \pm 23.8 \mathrm{~cm} / \mathrm{s}$, and the mean RI was $0.35 \pm 0.12$ and $0.45 \pm 0.11$, respectively. All the abovementioned clinical and ultrasound parameters between the case group and the control group showed significant differences (Table 3).

The results of further multivariable logistic regression analyses are shown in Table 4. Statistically significant higher ORs were found for the gestational mass size (OR 3.624, 95\% CI [1.179-11.138]) and the PSV (OR 1.062, 95\% CI [1.007-1.121]) in the case group. Statistically significant lower ORs were found for the uterine scar thickness (OR $0.181,95 \%$ CI [0.034-0.957]) and the RI value (OR 0.851, 95\% CI [0.729-0.994]). However, the gestational age at diagnosis and the pretreatment serum $\beta$-HCG level did not show significant differences statistically.

\section{Discussion}

Although many treatments have been suggested for CSP, severe hemorrhage still occurs in some patients. Various hemostatic measures have been used for prevention and control of profuse bleeding, such as local injection of vasopressin, intrauterine balloon tamponade, bilateral uterine artery ligation, and UAE. ${ }^{11,12}$ Even though, a small part of patients still experience excessive bleeding, even resulting in hysterectomy and loss of future fertility. Therefore, exploring and understanding the risk factors for severe hemorrhage in the treatment of CSP has a great significance in helping us counsel such patients and choose appropriate therapeutic interventions.

Color Doppler ultrasonography has widespread application in the diagnosis and treatment of CSP. It is a noninvasive, radiation-free, cost-effective technique that can be easily performed and frequently repeated. Ultrasound images could provide information on the size of gestational mass and the thickness of cesarean scar, as well as excellent visualization of the blood supply. ${ }^{13}$ Previous grading system of blood flow (absent or mild, moderate, significant) is semiquantitative, made subjectively by physicians. Recently, ultrasound quantification of blood flow has been developed. In addition to qualitative analysis of spectrograms identifying characteristic blood flow patterns, quantitative variables such as arterial PSV and RI are also detected and calculated. ${ }^{14} \mathrm{RI}$ reflects the resistance to blood flow in the vessel influenced by vasoconstriction, dilation, or external vascular compression. PSV is influenced by respiratory variability, but RI, unlike measure of maximal and minimal velocities, is a ratio that is not altered by the angle of the Doppler and takes into account the direction and volume of blood flow. Therefore, the monitoring of both PSV and RI could reduce the interobserver bias between patients. ${ }^{14}$

Table 3 High-risk factors for excessive hemorrhage during the management of CSP

\begin{tabular}{llll}
\hline Parameters & $\begin{array}{l}\text { CSP with heavy } \\
\text { hemorrhage (mean } \pm \text { SD) }\end{array}$ & $\begin{array}{l}\text { CSP without heavy } \\
\text { hemorrhage (mean } \pm \text { SD) }\end{array}$ & $\begin{array}{c}\text { P-value } \\
\text { Hemorrhage volume }(\mathrm{mL})\end{array}$ \\
Gestational age at diagnosis (days) & $\mathrm{I}, 440 \pm 955$ & $215 \pm 84$ & $0.00 \mathrm{I}$ \\
Pretreatment serum $\beta$-HCG level $(\mathrm{mlU} / \mathrm{mL})$ & $74.1 \pm 23.6$ & $57.3 \pm 22.3$ & 0.004 \\
Gestational mass size $(\mathrm{cm})$ & $46,20 \mathrm{I} \pm 32,294$ & $24,189 \pm 10,584$ & 0.023 \\
Uterine scar thickness $(\mathrm{cm})$ & $6.5 \pm 2.2$ & $3.1 \pm 1.2$ & $<0.00 \mathrm{I}$ \\
PSV $(\mathrm{cm} / \mathrm{s})$ & $0.17 \pm 0.12$ & $0.3 \mathrm{I} \pm 0.15$ & $<0.00 \mathrm{I}$ \\
RI & $72.8 \pm 33.7$ & $47.5 \pm 23.8$ & $<0.00 \mathrm{I}$ \\
\hline
\end{tabular}

Abbreviations: CSP, cesarean scar pregnancy; SD, standard deviation; HCG, human chorionic gonadotropin; PSV, peak systolic velocity; RI, resistance index. 
Table 4 Results from multivariable logistic regression analysis of ORs, together with $95 \% \mathrm{Cls}$, for the risk of excessive hemorrhage

\begin{tabular}{|c|c|c|}
\hline Parameters & $P$-value & OR $(95 \% \mathrm{Cl})$ \\
\hline $\begin{array}{l}\text { Gestational age at diagnosis } \\
\text { (days) }\end{array}$ & 0.108 & 1.047 (0.990-I.I07) \\
\hline $\begin{array}{l}\text { Pretreatment serum } \\
\beta-H C G \text { level }(\mathrm{mlU} / \mathrm{mL})\end{array}$ & 0.955 & $1.000(1.000-1.000)$ \\
\hline Gestational mass size $(\mathrm{cm})$ & 0.025 & $3.624(1.179-11.138)$ \\
\hline Uterine scar thickness $(\mathrm{cm})$ & 0.044 & $0.181(0.034-0.957)$ \\
\hline $\mathrm{PSV}(\mathrm{cm} / \mathrm{s})$ & 0.026 & $1.062(1.007-1.121)$ \\
\hline $\mathrm{RI}$ & 0.042 & 0.85 I (0.729-0.994) \\
\hline
\end{tabular}

Note: Bold indicates $P<0.05$.

Abbreviations: $\mathrm{OR}$, odds ratio; $\mathrm{Cl}$, confidence interval; $\mathrm{HCG}$, human chorionic gonadotropin; PSV, peak systolic velocity; RI, resistance index.

In our study, we compared six parameters potentially related to hemorrhage, including two clinical parameters and four ultrasound parameters. Single-variable statistical analyses showed that the case group had larger gestational age, higher pretreatment serum $\beta$-HCG level, larger gestational mass size, thinner uterine scar thickness, and richer peritrophoblastic perfusion. Further multivariable logistic regression analysis of the association between each of the risk factors and hemorrhage confirmed that increased gestational mass size and PSV were risk factors for hemorrhage and increased uterine scar thickness and RI were protective factors against hemorrhage.

The results of the four ultrasonographic parameters in our research are consistent with several previous studies. ${ }^{15,16}$ Large gestational mass size could involve abundant blood supply, resulting in much more blood loss during the procedure. ${ }^{15}$ Thin myometrial layer between the gestational mass and the bladder presented with an elevated risk of rupture and bleeding. ${ }^{16,17}$

Peritrophoblastic perfusion has a strong association with hemorrhage, and its importance has been paid more and more attention on. The cesarean scar is due to lack of decidual tissue, and it is easy for the chorionic tissue to implant into the myometrium layer of the uterus, resulting in rich blood perfusion around the gestational mass., ${ }^{418}$ Grading of blood flow could reflect the density of newly formed blood vessels and decide the possibility of vascular rupture, predicting the risk of hemorrhage. ${ }^{4,18}$ To our best knowledge, there has been little information about quantitative parameters for peritrophoblastic perfusion. In our study, we detected and collected two quantitative parameters, PSV and RI, to evaluate the risk of massive hemorrhage. It is observed that higher PSV and lower RI are independent risk factors for uncontrollable hemorrhage, with OR 1.062 (1.007-1.121) and 0.851 (0.729-0.994), respectively.
However, the two clinical parameters, gestational age at diagnosis and pre-treatment serum $\beta$-HCG level, were not independent risk factors for severe hemorrhage after multivariable regression analyses. Whether these two parameters are associated with massive hemorrhage during the procedure is still controversial. ${ }^{7,8}$ It is possible that, since the gestational mass implants in the cesarean scar, maldevelopment of chorionic villi may cause disproportion to the gestational age and blood flow. Serum $\beta$-HCG level is a biochemical index reflecting the activity of trophoblastic cells, but lower activity of trophoblastic cells could be accompanied by abundant neovascularization. In addition, our sample size was small, and further studies with larger sample sizes should be performed.

Our study also had some limitations. First, there might be other risk factors that we did not consider but could influence the final results of multivariable logistic regression analyses. Second, although four independent risk factors for excessive hemorrhage were identified, our study did not put forward a practicable and easy-to-use evaluation protocol that could help clinicians to assess and identify patients at a high risk of massive bleeding and to assist decision-making for the treatment of CSP. Third, further prospective studies in multiple medical institutions will be needed to validate our research findings.

\section{Conclusion}

During the management of CSP, gestational mass size $>6 \mathrm{~cm}$, uterine scar thickness $<0.2 \mathrm{~cm}$, PSV $>70 \mathrm{~cm} / \mathrm{s}$, and RI $<0.35$ are independent risk factors for excessive hemorrhage.

\section{Acknowledgment}

This study was supported by the Capital Medical Development Foundation of China (No 2016-2-4015) and National Natural Science Foundation of China (No 81402140). The authors thank Dr Zhenzhen Liu and Dr Xining Wu for their assistance in relation to ultrasound examination of cesarean scars in pregnancy.

\section{Disclosure}

The authors report no conflicts of interest in this work.

\section{References}

1. Jurkovic D, Hillaby K, Woelfer B, Lawrence A, Salim R, Elson CJ. First trimester diagnosis and management of pregnancies implanted into the lower uterine segment cesarean section scar. Ultrasound Obstet Gynecol. 2003;21(3):220-227.

2. Jurkovic D, Hillaby K, Woelfer B, Lawrence A, Salim R, Elson CJ. Cesarean scar pregnancy. Ultrasound Obstet Gynecol. 2003;21(3):310. 
3. Timor-Tritsch IE, Monteagudo A. Unforeseen consequences of the increasing rate of cesarean deliveries: early placenta accreta and cesarean scar pregnancy. A review. Am J Obstet Gynecol. 2012;207(1): 14-29.

4. Timor-Tritsch IE, Monteagudo A, Santos R, Tsymbal T, Pineda G, Arslan AA. The diagnosis, treatment, and follow-up of cesarean scar pregnancy. Am J Obstet Gynecol. 2012;207(1):44.e1-44.e13.

5. Rotas MA, Haberman S, Levgur M. Cesarean scar ectopic pregnancies: etiology, diagnosis, and management. Obstet Gynecol. 2006;107(6): 1373-1381.

6. Litwicka K, Greco E. Cesarean scar pregnancy: a review of management options. Curr Opin Obstet Gynecol. 2011;23:415-421.

7. Du YJ, Zhang XH, Wang LQ. Risk factors for hemorrhage during suction curettage after uterine artery embolization for treating cesarean scar pregnancy: a case-control study. Gynecol Obstet Invest. 2015; 80(4):259-264.

8. Wang Q, Ma H, Peng H, He L, Bian C, Zhao X. Risk factors for intraoperative hemorrhage and bleeding risk scoring system for cesarean scar pregnancy: a case-control study. Eur J Obstet Gynecol Reprod Biol. 2015;195:141-145

9. Li KN, Dai Q, Liu ZZ, Su N, Wang M, Jiang YX. Clinical value of ultrasonography in predicting massive hemorrhage during cesarean scar pregnancy. Zhongguo Yi Xue Ke Xue Yuan Xue Bao. 2015;37: 585-590.

10. Godin PA, Bassil S, Donnez J. An ectopic pregnancy developing in a previous cesarean section scar. Fertil Steril. 1997;67:398-400.

11. Jiang T, Liu G, Huang L, Ma H, Zhang S. Methotrexate therapy followed by suction curettage followed by Foley tamponade for caesarean scar pregnancy. Eur J Obstet Gynecol Reprod Biol. 2011;156(2): 209-211.
12. Le A, Shan L, Xiao T, Zhuo R, Xiong H, Wang Z. Transvaginal surgical treatment of cesarean scar ectopic pregnancy. Arch Gynecol Obstet. 2013;287(4):791-796.

13. Bij de Vaate AJ, Brolmann HA, van der Voet LF, van der Slikke JW, Veersema S, Huime JA. Ultrasound evaluation of the cesarean scar: relation between a niche and postmenstrual spotting. Ultrasound Obstet Gynecol. 2011;37(1):93-99.

14. Riggs BJ, Cohen JS, Shivakumar B, et al. Doppler ultrasonography of the central retinal vessels in children with brain death. Pediatr Crit Care Med. 2017;18(3):258-264.

15. Wang JH, Qian ZD, Zhuang LY, Du YJ, Zhu LH, Huang LL. Risk factors for intraoperative hemorrhage at evacuation of a cesarean scar pregnancy following uterine artery embolization. Int J Gynecol Obstet. 2013;123(3):240-243.

16. Shao MJ, Hu MX, Xu XJ, Zhang L, Hu M. Management of cesarean scar pregnancies using an intrauterine or abdominal approach based on the myometrial thickness between the gestational mass and the bladder wall. Gynecol Obstet Invest. 2013;76:151-157.

17. Chen WL, Jin L. Successful treatment of endogenous cesarean scar pregnancies with transabdominal ultrasound-guided suction curettage alone. Eur J Obstet Gynecol Reprod Biol. 2014;183:20-22.

18. Zhai JF, Xu M, Zhang B, Gao JW, Chen N. Treatments of cesarean scar pregnancy and the corresponding results in ten years. Eur Rev Med Pharmacol Sci. 2015;19(14):2523-2527.
Therapeutics and Clinical Risk Management

\section{Publish your work in this journal}

Therapeutics and Clinical Risk Management is an international, peerreviewed journal of clinical therapeutics and risk management, focusing on concise rapid reporting of clinical studies in all therapeutic areas outcomes, safety, and programs for the effective, safe, and sustained use of medicines. This journal is indexed on PubMed Central, CAS,

\section{Dovepress}

EMBase, Scopus and the Elsevier Bibliographic databases. The manuscript management system is completely online and includes a very quick and fair peer-review system, which is all easy to use. Visit http://www.dovepress.com/testimonials.php to read real quotes from published authors. 